\title{
Mollugin attenuates glucocorticoid-induced osteoporosis in rats via Akt/P13K pathway
}

\author{
Zhen Jia*, Ge Yan, Yusi Wang, Pan He \\ Department of Traumatology, Hunan Provincial People's Hospital, The First Affiliated Hospital of Hunan Norma, Changsha, \\ Hunan, 410005, China
}

*For correspondence: Email: jiazhen63@hotmail.com; Tel: 0086-0731-83929409

\begin{abstract}
Purpose: To investigate the protective effect of mollugin on glucocorticoid (GC)-induced osteoporosis in rats.

Methods: A total of 30 female Sprague Dawley rats (weighing 180 to $200 \mathrm{~g}$ ) were randomly assigned to five groups of six rats each: control, GC and mollugin groups (20, 40 and $80 \mathrm{mg} / \mathrm{kg}$, respectively). Except for the control group, osteoporosis was induced in the rats by intramuscular administration of dexamethasone at a dose of $2.5 \mathrm{mg} / \mathrm{kg}$ twice weekly for nine weeks. Bone mineral density (BMD) and serum activities of tartrate-resistant acid phosphatase (TRAP) and specific alkaline phosphatase (ALP), and levels of collagen type I fragment (CTX) and osteocalcin were estimated. The effect of mollugin alone, and in the presence of PI3K/Akt inhibitor on the proliferation of bone marrow osteoblasts was investigated using 3-(4, 5-dimethylthiazol-2-yl)-2, 5-tetrazolium bromide (MTT) assay. Western blotting was used for determination of the expressions of $p$-Akt, Akt and cyclin D1 protein.

Results: There were significant increases in body weights of rats in GC group, when compared with the control group. However, treatment with mollugin significantly reduced the body weights in a dosedependent manner $(p<0.05)$. The BMD was significantly reduced in $G C$ group, relative to the control group $(p<0.05)$. Serum activities of TRAP and ALP were significantly higher in GC group than in control group, but were significantly reduced by mollugin treatment $(p<0.05)$. Serum level of CTX was significantly increased and osteocalcin reduced in the GC group, relative to control $(p<0.05)$. Osteoblast proliferation was significantly higher in the mollugin-treated groups. The expressions of $p$ $A k t$, Akt and cyclin D1 were significantly and dose-dependently higher in mollugin-treated groups $(p<$ 0.05). There were more viable osteoblasts in the mollugin-treated groups than in the untreated group. However, treatment with mollugin in the presence of PIJK/Akt inhibitor significantly reduced their viability $(p<0.05)$.

Conclusion: Mollugin has therapeutic potential for GC-induced osteoporosis via mechanism involving the PIЗK/Akt pathway.
\end{abstract}

Keywords: Mollugin, Osteoporosis, Bone, PI3K/Akt inhibitor, Osteoblast

This is an Open Access article that uses a funding model which does not charge readers or their institutions for access and distributed under the terms of the Creative Commons Attribution License (http://creativecommons.org/licenses/by/4.0) and the Budapest Open Access Initiative (http://www.budapestopenaccessinitiative.org/read), which permit unrestricted use, distribution, and reproduction in any medium, provided the original work is properly credited.

Tropical Journal of Pharmaceutical Research is indexed by Science Citation Index (SciSearch), Scopus, International Pharmaceutical Abstract, Chemical Abstracts, Embase, Index Copernicus, EBSCO, African Index Medicus, JournalSeek, Journal Citation Reports/Science Edition, Directory of Open Access Journals (DOAJ), African Journal Online, Bioline International, Open-J-Gate and Pharmacy Abstracts

\section{INTRODUCTION}

Osteoporosis is a metabolic disorder that results in decreases in the mass and quality of bone; and deterioration of bone architecture [1].
Glucocorticoids (GCs) are used for the treatment of several chronic disorders such as cancer, gastrointestinal and autoimmune diseases [2]. However, chronic use of glucocorticoids leads to the development of secondary osteoporosis [3]. 
A balance between functions of osteocytes and osteoblasts is responsible for bone remodeling. These cells are the targets of glucocorticoids which induce apoptosis in them via a redox pathway [4]. Chronic use of glucocorticoids inhibits the maturation and proliferation of osteoblasts [5]. Drugs used for the treatment of osteoporosis are very few. Studies have shown that several naturally-occurring compounds exert anti-osteoporotic effect by acting as antioxidants.

Mollugin is a naphthohydroquine isolated from Rubia cordifolia (Rubiaceae); a herb used in traditional Chinese medicine for the treatment of several chronic disorders including osteoporosis $[6,7]$. Studies have shown that mollugin possesses antiviral, anti-cancer and antiinflammatory properties [8,9]. Its neuroprotective effect is exerted through the inflammatory pathway [10]. Mollugin inhibits collagen and arachidonic acid pathways thereby preventing platelet aggregation [10]. The aim of this study was to investigate the protective effect of mollugin on glucocorticoid-induced osteoporosis in rats.

\section{EXPERIMENTAL}

\section{Materials}

Dexamethasone was product of Tianjin Pharmaceutical Group Xinzheng Co., Ltd., Zhengzhou, China; ALP and TRAP kits were purchased from Nanjing Jiancheng Bioengineering Institute, Nanjing, China. TRAP microplate reader $(E L X-800)$ was purchased from Bio-Tek Instruments, Winooski, VT, USA). Osteocalcin and CTX ELISA kits were products of USCN Life Science, Wuhan, China; Dulbecco's Modified Essential Medium (DMEM) was obtained from Gibco Life Technologies, Carlsbad, CA, USA), while fetal bovine serum (FBS) was from HyClone, Logan, UT, USA. Radio-immunoprecipitation (RIPA) lysis buffer, and horseradish peroxidase-labeled goat antirabbit IgG and bicinchoninic acid (BCA) protein assay kits were purchased from Beyotime Institute of Biotechnology, Haimen, China. Polyvinylidene difluoride (PVDF) membranes were products of Millipore, Bedford, MA, USA, while $\beta$-actin, p-Akt, Akt and cyclin D1 were obtained from Santa Cruz Biotechnology, Inc., Dallas, TX, USA.

\section{Animals}

A total of 30 female Sprague Dawley rats weighing between 180 and $200 \mathrm{~g}$ were procured from Shanghai Medical College, China. They were housed under controlled conditions (temperature: $25 \pm 2{ }^{\circ} \mathrm{C}$; humidity: $60 \pm 5 \%$; and $12 \mathrm{~h}$ light/dark cycle). The study protocol was approved by Institutional Animal Care and Use Committee (IACUC) of Hunan Provincial People's Hospital, the First Affiliated Hospital of Hunan Norma, China, and followed the guidelines of Association for the Assessment and Accreditation of Laboratory Animal Care International (AAALAC) for experimentation and animal use [11]. The rats were randomly assigned to five groups of six rats each: control, $\mathrm{GC}$, mollugin $(20 \mathrm{mg} / \mathrm{kg})$, mollugin $(40 \mathrm{mg} / \mathrm{kg})$, and mollugin $(80 \mathrm{mg} / \mathrm{kg})$. Except for rats in the control group, osteoporosis was induced in all rats by intramuscular administration of $2.5 \mathrm{mg} / \mathrm{kg}$ bwt dexamethasone twice a week for nine weeks, and body weights of the rats were measured on weekly basis.

\section{Sample collection}

At the end of the treatment period, blood was collected from the rats through retroorbital puncture, and centrifuged at $2000 \mathrm{rpm}$ for $20 \mathrm{~min}$ to obtain serum samples used for biochemical analyses. The rats were sacrificed by cervical dislocation and their femurs excised and used for analysis.

\section{Determination of bone mineral density (BMD)}

Dual-energy x-ray absorptiometry bone densitometry was used for the estimation of BMD. The measurement was done in triplicate and the mean calculated.

\section{Measurement of the activities of TRAP and ALP}

Activities of TRAP and ALP were determined using their respective kits according to the instructions of the manufacturers. Microplate reader was used to read absorbance at wavelengths of $530 \mathrm{~nm}$ (TRAP) and $520 \mathrm{~nm}$ (ALP).

\section{Assessment of collagen type I fragment and osteocalcin}

Enzyme-linked immunosorbent assay (ELISA) was used for the estimation of collagen type I fragment and osteocalcin according to the instructions of kits manufacturers.

\section{Cell culture}

Sprague-Dawley rats of either sex aged 2 months or less were procured from Beijing Institute of Medical Sciences, China and used for primary osteoblast cell culture. The rats were 
sacrificed and their bones (tibia and femur) excised. The bone marrows were flushed with 5 $\mathrm{ml}$ of phosphate-buffered saline (PBS), followed by the addition of lymphocyte separation medium, and centrifuged at $2000 \mathrm{rpm}$ for $20 \mathrm{~min}$ to obtain mononucleated cells. Fetal bovine serum-supplemented DMEM was added to the isolated cells and incubated at $37{ }^{\circ} \mathrm{C}$ in an incubator. The culture medium was replaced with fresh medium every three days and the cells were trypsinized after attaining $80 \%$ confluency. Differentiation of osteoblasts was induced by adding $1 \times 10^{4}$ cells into 96-well plates filled with osteoblast differentiation medium. The positive control group (cells that were not treated with mollugin nor exposed to standard medium and so had no differentiation factors) were treated with concentrations of mollugin ranging from 0 $10 \mu \mathrm{M}$.

\section{Determination of cell viability (MTT assay)}

The viability of cells i.e. their ability to reduce tetrazolium salts was determined using MTT assay. The cells $\left(1 \times 10^{4}\right.$ cells/well) were seeded into a 96-well plate by adding DMEM and were incubated for $24 \mathrm{~h}$. Mollugin $(0-10 \mu \mathrm{M})$ was added to the cells and they were further incubated for 3 days. At the end of the third day, $20 \mu \mathrm{l}$ of MTT solution was added to the wells, followed by incubation for another $4 \mathrm{~h}$. The medium was finally replaced with dimethyl sulfoxide (DMSO) solution, agitated at 50 oscillations/min for $10 \mathrm{~min}$, and absorbance of the samples were read using a microplate reader at $450 \mathrm{~nm}$.

\section{Western blotting}

The cells treated with mollugin $(0-10 \mu \mathrm{M})$ were washed with PBS and ice-cold radioimmunoprecipitation assay buffer (RIPA) was used to lyse them. Determination of protein content was done using BCA protein assay kit. Protein separation was achieved with sodium dodecyl sulfate-polyacrylamide gel electrophoresis (SDS-PAGE) and the bands transferred to PVDF membranes. Membranes with target proteins were incubated with primary antibodies ( $\mathrm{p}$-Akt, Akt, cyclin D1 and $\beta$-actin), washed and subsequently incubated with horseradish peroxidase-conjugated secondary antibodies. The densities of the bands were estimated using Chemi-doc XRS imaging system.

\section{Statistical analysis}

Data are expressed as mean \pm SEM. The statistical analysis was performed using
Graphpad Prism (6.1). Groups were compared using Dunnett's post-hoc test. Values of $p<0.05$, were considered statistically significant.

\section{RESULTS}

\section{Effect of mollugin on body weight and BMD}

The body weights of rats increased significantly in GC group, relative to the control. However, they were significantly reduced in a dosedependent manner after treatment with mollugin $(p<0.05)$. Measurement of BMD was done before and after treatment. It was significantly reduced in GC group when compared to control group, but the reduction was significantly reversed with mollugin treatment $(p<0.05)$, as shown in Figure 1.
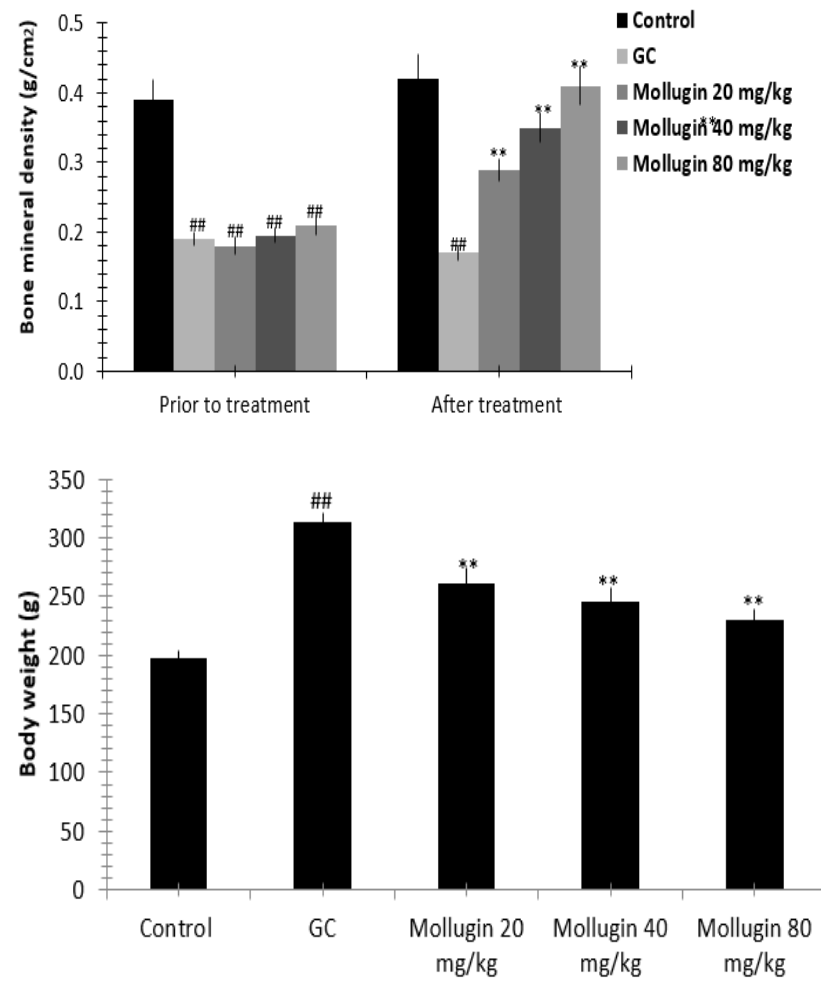

Figure 1: Effect of mollugin on body weight and BMD in GC-induced osteoporotic rats. ${ }^{\# \#} p<0.01$, compared to control group; ${ }^{*} p<0.05,{ }^{* *} p<0.01$, compared to GC group

\section{Effect of mollugin on the activities of TRAP and ALP}

Serum activities of bone-specific TRAP and ALP were significantly higher in GC group than in control group, but was significantly reduced with mollugin treatment $(p<0.05)$, as shown in Figure 2. 

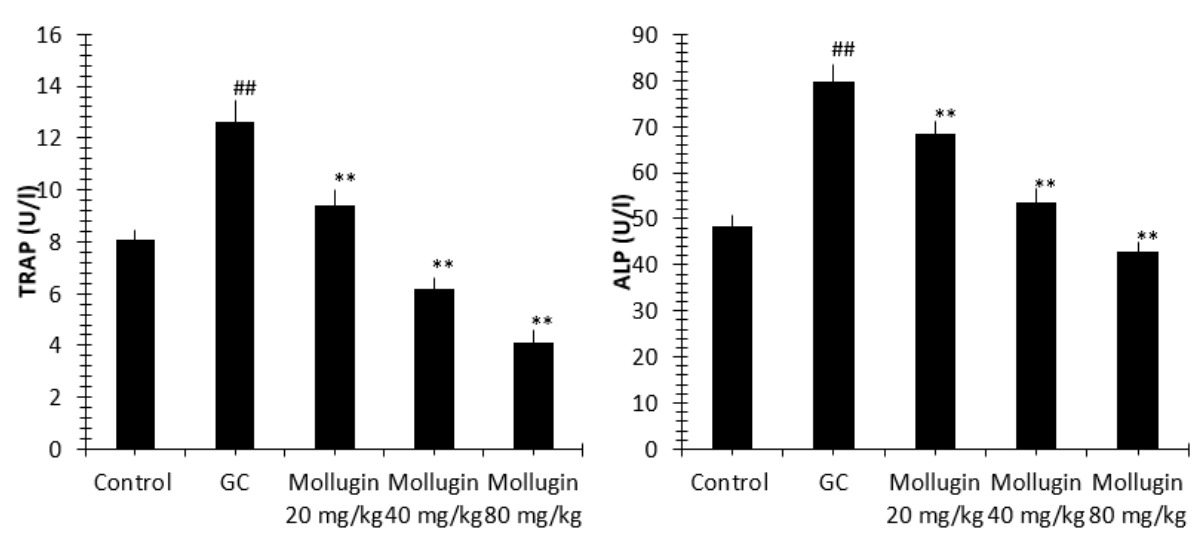

Figure 2: Effect of mollugin on serum activities of TRAP and ALP in GC-induced osteoporotic rats. ${ }^{\# \#} p<0.01$, compared to control group; ${ }^{*} p<0.05,{ }^{* *} p<0.01$, compared to GC group

\section{Effect of mollugin on the levels of CTX and osteocalcin}

Serum level of CTX was significantly increased while serum osteocalcin was reduced in the GC group, when compared with the control group ( $p$ $<0.05)$. However, treatment with mollugin significantly reversed the altered levels of these biomarkers (Figure 3).
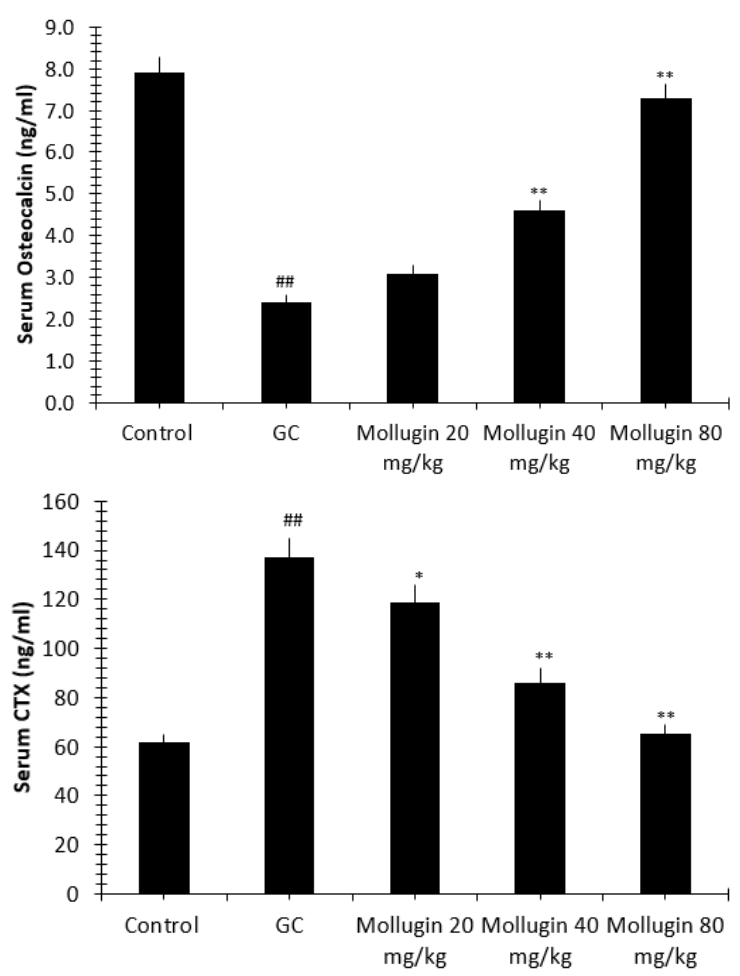

Figure 3: Effect of mollugin on serum levels of CTX and osteocalcin in osteoporotic rats; \# $p<0.01$, compared to control group; ${ }^{*} p<0.05,{ }^{\star *} p<0.01$, compared to GC group

\section{Effect of mollugin on the proliferation of osteoblasts}

The proliferation of osteoblasts was significantly higher in mollugin-treated groups than in the untreated group $(p<0.05$, Figure 4$)$.

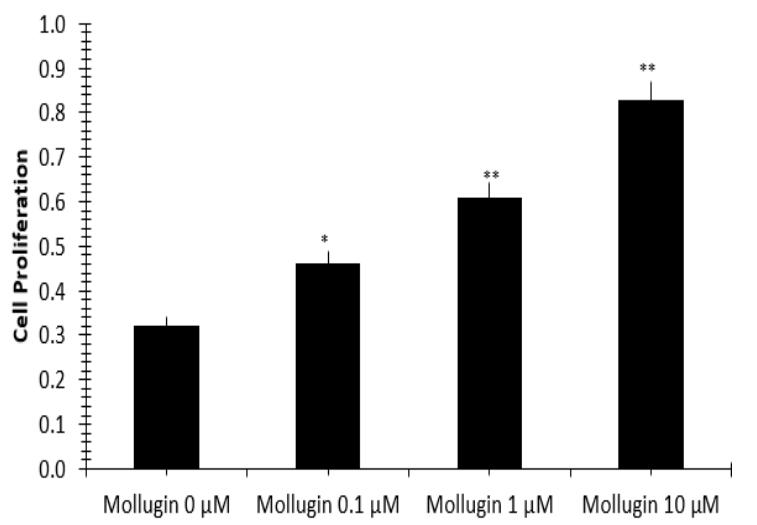

Figure 4: Effect of different concentrations of mollugin on the proliferation of osteoblasts; ${ }^{\# \#} p<0.01$, compared to control group, ${ }^{*} p<0.05,{ }^{* \star} p<0.01$, compared to untreated group

\section{Effect of mollugin on expressions of p-Akt, Akt and cyclin D1}

The expressions of $p-A k t$, Akt and cyclin D1 were significantly and dose-dependently higher in mollugin-treated groups than in the untreated group $(p<0.05$, Figure 5$)$.

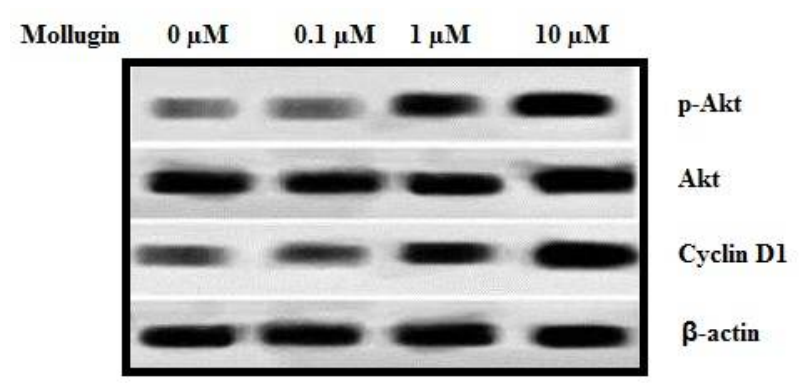

Figure 5: Expressions of p-Akt, Akt and cyclin D1 proteins in mollugin-treated groups

Trop J Pharm Res, September 2018; 17(9): 1768 
Effect of mollugin on the viability of osteoblasts

There were more viable osteoblasts in mollugintreated groups than in the untreated group. However, treatment with mollugin in the presence of PI3K/Akt inhibitor significantly reduced their viability (Figure 6).

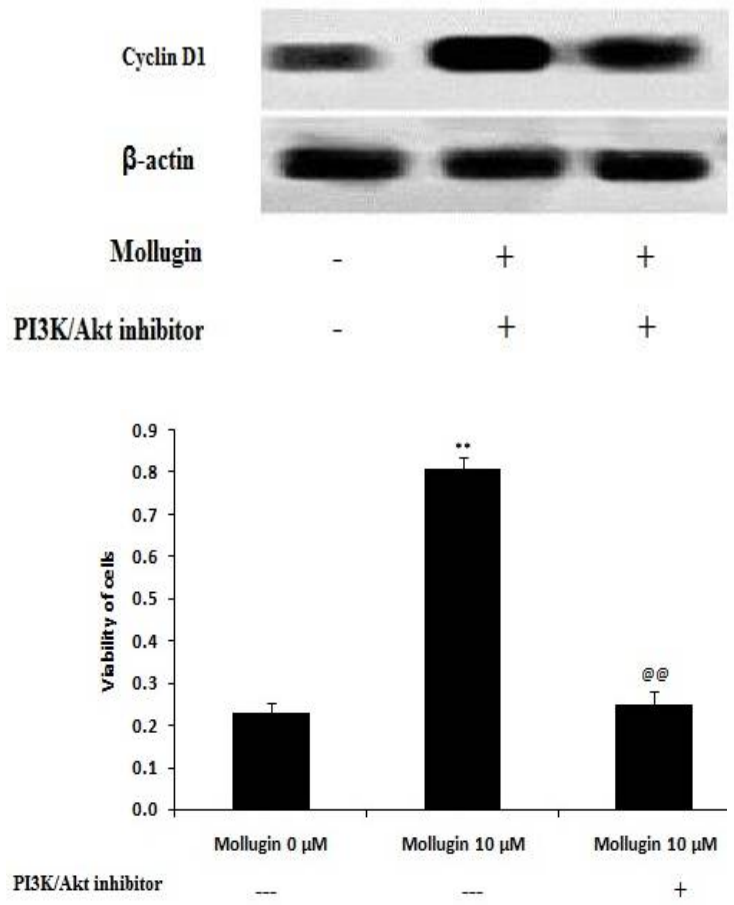

Figure 6: Effect of mollugin on viability of osteoblasts in the presence of PI3K/Akt inhibitor. ${ }^{* *} p<0.01$, compared to untreated group; ${ }^{@ @ ~} p<0.0$, compared to $10 \mu \mathrm{M}$ mollugin-treated group

\section{DISCUSSION}

Osteoporosis is characterized by deterioration of bone microarchitecture and reduction in bone mass due to decrease in the BMD. Thus, drugs that prevent reduction of BMD are used for its treatment [12,13]. In the present study, body weights of rats increased significantly in GC group, when compared to control. However, body weight increases were significantly reduced in a dose-dependent manner after treatment with mollugin, and the treatment significantly reversed the decrease in BMD caused by osteoporosis.

In osteoporosis, the balance between bone formation and resorption is altered; while CTX is the marker for bone resorption, osteocalcin is the marker for bone formation [14]. The altered serum levels of CTX and osteocalcin were significantly reversed by treatment with mollugin. The activities of TRAP (marker for bone resorption) and ALP in osteoblasts are significantly altered in osteoporosis [15]. In this study, treatment with mollugin significantly reversed the altered activities of TRAP and ALP in osteoporotic rats. Studies have shown that drugs used in the treatment of osteoporosis usually induce the proliferation of osteoblasts [16].

In the present study, proliferation of osteoblasts was significantly higher in mollugin-treated groups than in the untreated group. Some authors have speculated that PI3K/Akt pathway plays an important role in the proliferation and differentiation of osteoblasts [17]. The results obtained in the present study showed that the proliferation of osteoblasts was significantly reduced in mollugin and $\mathrm{PI} / 3 \mathrm{~K} / \mathrm{Akt}$ inhibitortreated group than in mollugin alone-treated group.

\section{CONCLUSION}

Mollugin has therapeutic potential for the treatment of GC-induced osteoporosis, and its anti-osteoporotic effect occurs via PI3K/Akt pathway.

\section{DECLARATIONS}

\section{Acknowledgement}

All the author of this manuscript thankful to Hunan Provincial People's Hospital, The First Affiliated Hospital of Hunan Norma, China for providing funding for this work.

\section{Conflict of interest}

No conflict of interest is associated with this study.

\section{Contribution of authors}

We declare that this work was done by the authors named in this article and all liabilities pertaining to claims relating to the content of this article will be borne by the authors. Zhen Jia designed the project, supervised the experiments and wrote the manuscript, Ge Yan, Yusi Wang and $\mathrm{Pan} \mathrm{He}$ analysed the data and provided comments.

\section{REFERENCES}

1. Demontiero O, Vidal C, Duque G, Aging and bone loss: new insights for the clinician. Ther Adv Musculoskelet Dis 2012; 4(2): 61-76.

2. Criscitiello $C$, Bagnardi V, Esposito A, Gelao L, Santillo B, Viale G, Rotmensz N, Goldhirsch A, Curigliano G, 
Impact of autoimmune diseases on outcome of patients with early breast cancer. Oncotarget. 2016; 7(32): 51184-51192.

3. Fraser LA, Adachi JD, Glucocorticoid-Induced Osteoporosis: Treatment Update and Review. Ther Adv Musculoskelet Dis 2009; 1(2): 71-85.

4. Pacifici $R, T$ cells, osteoblasts, and osteocytes: interacting lineages key for the bone anabolic and catabolic activities of parathyroid hormone. Ann NY Acad Sci 2016; 1364(1): 11-24.

5. Cárcamo-Orive I, Gaztelumendi A, Delgado J, Tejados N, Dorronsoro A, Fernández-Rueda J, Pennington DJ, Trigueros $C$. Regulation of human bone marrow stromal cell proliferation and differentiation capacity by glucocorticoid receptor and AP-1 crosstalk. J Bone Miner Res. 2010; 25(10): 2115-2125.

6. Bhatt $P$, Kushwah AS. Rubiacordifolia Overview: A New Approach to Treat Cardiac Disorders. Int. J. Drug Dev. \& Res., 2013; 5(2): 47-54

7. Saha S, Ghosh S. Tinosporacordifolia: One plant, many roles. Anc Sci Life. 2012; 31(4): 151-159.

8. Wang Z, Li MY, Mi C, Wang KS, Ma J, Jin X. Mollugin Has an Anti-Cancer Therapeutic Effect by Inhibiting TNF- $\alpha$-Induced NF-KB Activation. Int J Mol Sci. 2017; 18(8). pii: E1619.9.

9. Kim H, Choi HK, Jeong TC, Jahng $Y$, Kim DH, Lee SH, Lee $S$. Selective inhibitory effects of mollugin on CYP1A2 in human liver microsomes. Food ChemToxicol. 2013; 51: 33-37.

10. Jeong GS, Lee DS, Kim DC, Jahng Y, Son JK, Lee SH, Kim YC, Neuroprotective and anti-inflammatory effects of mollugin via up-regulation of heme oxygenase-1 in mouse hippocampal and microglial cells., Eur $J$ Pharmacol. 2011; 654(3): 226-234.

11. Guide for the Care and Use of Laboratory Animals: Eighth Edition Committee for the Update of the Guide for the Care and Use of Laboratory Animals; National Research Council. 2010; ISBN: 0-309-15401-4.

12. Sözen T, Özışık L, Başaran NÇ. An overview and management of osteoporosis. Eur J Rheumatol. 2017; 4(1): 46-56.

13. Panday K, Gona A, Humphrey MB. Medication-induced osteoporosis: screening and treatment strategies. Ther Adv Musculoskelet Dis. 2014; 6(5): 185-202.

14. Wheater G, Elshahaly M, Tuck SP, Datta HK, van Laar $J M$. The clinical utility of bone marker measurements in osteoporosis. J Trans/Med. 2013; 11: 201.

15. Zhai $Y-K$, Pan $Y$-L, Niu Y-B, Li CR, Wu XL, Fan WT, Lu $T L$, Mei QB, Xian CJ. The Importance of the Prenyl Group in the Activities of Osthole in Enhancing Bone Formation and Inhibiting Bone Resorption In Vitro. Int $J$ Endocrinol 2014; 2014: 921954.

16. Dvorak MM, De Joussineau C, Carter DH, Pisitkun $T$, Knepper MA, Gamba G, Kemp PJ, Riccardi D. Thiazide diuretics directly induce osteoblast differentiation and mineralized nodule formation by targeting a $\mathrm{NaCl}$ cotransporter in bone. J Am Soc Nephrol. 2007; 18(9): 2509-2516.

17. Liu G, Deng C, The PI3K/Akt Signalling Pathway Plays Essential Roles in Mesenchymal Stem Cells. Br Biomed Bull 2017; 5: 301. 